Jurnal Keperawatan Silampari

Volume 3, Nomor 1, Desember 2019

e-ISSN :2581-1975

p-ISSN :2597-7482

DOI: https://doi.org/10.31539/jks.v3i1.809

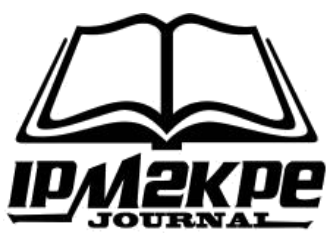

\title{
HASIL SKRINING PERKEMBANGAN ANAK USIA TODDLER ANTARA DDST DENGAN SDIDTK
}

\author{
Padila $^{1}$, Fatsiwi Nunik Andari ${ }^{2}$, Juli Andri ${ }^{3}$ \\ Program Studi Ilmu Keperawatan, Universitas Muhammadiyah Bengkulu 1,2,3 \\ Padila_ahmad@yahoo.co.id ${ }^{1}$
}

\begin{abstract}
ABSTRAK
Tujuan penelitian ini adalah menganalisis efektivitas hasil skrining deteksi dini perkembangan anak usia toddler antara intervensi denver developmental screening test (DDST) dengan stimulasi, deteksi dan intervensi dini tumbuh kembang (SDIDTK). Desain penelitian yang digunakan dalam penelitian ini yaitu dengan menggunakan rancangan Quasy eksperimen, pre-post test equivalent without control group design. Hasil analisis univariat sebelum dilakukan intervensi DDST masing-masing $3(30 \%)$ orang anak yang tahap perkembangannya abnormal dan meragukan dan hanya $4(40 \%)$ orang anak yang tahap perkembangannya normal, setelah dilakukan intervensi sebagian besar yaitu $7(70 \%)$ orang anak yang tahap perkembangannya normal. Sedangkan hasil sebelum dilakukan intervensi SDIDTK ada 2 (20\%) orang anak yang tahap perkembangannya abnormal dan masing-masing $4(40 \%)$ orang anak yang tahap perkembangannya normal dan meragukan, setelah dilakukan intervensi sebagian besar yaitu $7(70 \%)$ orang anak yang tahap perkembangannya normal. Hasil analisis bivariat menunjukkan bahwa terdapat peningkatan skor tahap perkembangan pada kelompok DDST dan pada kelompok SDIDTK dengan masing-masing ( $\mathrm{t}$ value $=-3,096, \mathrm{p}$ value $=0,013)$ dan $(\mathrm{t}$ value $=-2,703, \mathrm{p}$ value $=0,024)$. Simpulan hasil penelitian terdapat pengaruh yang signifikan antara skor tahap perkembangan pada kelompok DDST dan pada kelompok SDIDTK sebelum dan setelah dilakukan intervensi.
\end{abstract}

Kata Kunci : DDST II, Perkembangan, SDIDTK, Skrining, Toodler.

\section{ABSTRACT}

The purpose of this study was to analyze the effectiveness of screening results for early detection of toddler age development between denver developmental screening test (DDST) interventions with stimulation, detection and early developmental intervention (SDIDTK). The research design used in this study is to use an experimental Quasy design, pre-post test equivalent without control group design. The results of univariate analysis before DDST intervention were 3 (30\%) of the children whose stages of development were abnormal and doubtful and only 4 (40\%) of the children were normal developmental stages, after the intervention, which were mostly 7 (70\%) children whose stages of development are normal. While the results before SDIDTK intervention were 2 (20\%) children whose developmental stages were abnormal and 4 (40\%) of those children whose stages of development were normal and doubtful, after the intervention the majority were 7 (70\%) children normal developmental stage. The results of 
bivariate analysis showed that there was an increase in the score of developmental stages in the DDST group and in the SDIDTK group with each ( $t$ value $=-3.096, p$ value $=0.013)$ and $(t$ value $=-2.703, p$ value $=0.024)$. Conclusions of the results of the study there was a significant influence between the scores of the developmental stages in the DDST group and in the SDIDTKI group before and with after the intervention.

Keywords: DDST II, Development, SDIDTK, Screening, Toodler

\section{PENDAHULUAN}

Golden Age berada pada masa kanak-kanak antara usia 1-6 tahun, usia ini merupakan masa yang sangat penting bagi pertumbuhan dan perkembangan individu. Perkembangan merupakan suatu proses bertambahnya struktur, fungsi, dan kemampuan manusia yang lebih kompleks dalam pola yang teratur, sebagai hasil dari proses pematangan (Sulistyawati, 2014). Sama seperti pernyataan dari (Soetjiningsih \& IGN, 2015) yang menyatakan bahwa masa lima tahun pertama kehidupan merupakan masa yang sangat peka terhadap lingkungan dan masa ini berlangsung sangat pendek dan tidak bisa diulang kembali, masa ini sering juga disebut masa keemasan (Golden Period), jendela kesempatan (window of opportunity) dan masa kritis (Rahardjo, Wayanti, \& Wardani, 2019). Masa kanak-kanak memberi pengaruh yang besar pada individu dalam tahapan perkembangan selanjutnya. Anak toodler adalah anak yang berusia 1-3 tahun, yang pada umumnya kelompok anak tersebut sudah belajar percaya pada orang lain, mulai cepat meniru dan mengembangkan kemandirian membuka dan memakai baju, berjalan, mengambil, makan sendiri dan ke toilet mulai terbentuk kontrol diri. Jika perkembangan kemandirian toodler tidak didukung oleh orangtua, maka rerata anak akan memiliki kepribadian yang ragu-ragu, dan jika anak dibuat merasa buruk pada saat kegiatan stimulasi ia melakukan kegagalan, maka anak akan menjadi pemalu dan pendiam (Lestari \& Hati, 2016).

Kualitas generasi penerus bangsa tergantung dari kualitas tumbuh kembang anak, terutama usia toodler (1-3) tahun, dimana anak menunjukkan perkembangan otak yang sangat signifikan, keluarga harus mengupayakan agar anaknya dapat bertumbuh dan berkembang secara optimal untuk mengindari tumbuh kembang yang abnormal, meragukan ataupun menyimpang. Penyimpangan tumbuh kembang harus dideteksi (ditemukan) sejak dini, terutama sebelum berumur 3 tahun, supaya dapat segera di intervensi (diperbaiki), bila deteksi terlambat, maka penanganan terlambat, sehingga penyimpangan sukar untuk diperbaiki (Cecily L., Betz. Showden., 2009). Masa anak dianggap sebagai fase yang penting karena akan menentukan kualitas kesehatan, kesejahteraan, pembelajaran, dan perilaku dimasa yang akan dating serta masa depan masyarakat tergantung pada anak-anak yang mampu mencapai pertumbuhan dan perkembangan yang optimal (WHO, 2017).

Stimulasi adalah kegiatan merangsang kemampuan dasar anak umur 0-6 tahun agar anak tumbuh dan berkembang secara optimal. Setiap anak perlu mendapat stimulasi rutin sedini mungkin dan terus menerus pada setiap kesempatan. Stimulasi tumbuh kembang anak dilakukan oleh ibu dan ayah yang merupakan orang terdekat dengan anak, pengganti ibu dan pengasuh anak, anggota keluarga lain dan kelompok masyarakat di lingkungan rumah tangga masing-masing dan dalam kehidupan seharihari. Kurangnya stimulasi dapat menyebabkan penyimpangan tumbuh kembang anak bahkan gangguan yang menetap (Dewi \& Winarsih, 2017). Stimulus orang tua yang dilakukan terhadap anak harus diberikan secara terus menerus dan stimulasi 
membutuhkan alat sederhana sebagai obyek yang digunakan untuk merangsang perkembangan motorik anak (Kuncoro, 2013).

Upaya pemeliharaan kesehatan anak ditujukan untuk mempersiapkan generasi akan datang yang sehat, cerdas dan berkualitas serta untuk menurunkan angka kematian anak yang dilakukan sejak janin masih dalam kandungan, dilahirkan, setelah dilahirkan, dan sampai berusia 18 tahun (Rivanica, 2019; Rivanica, Rhipiduri, \& Oxyandi, 2016). Salah satu upaya penjaringan yang dilaksanakan secara komprehensif untuk mengetahui adanya penyimpangan pada tumbuh kembang anak serta untuk mengoreksi adanya faktor resiko adalah dengan deteksi dini. Dengan adanya faktor resiko yang telah diketahui, maka upaya untuk meminimalkan dampak pada anak bisa dicegah. Upaya tersebut diberikan sesuai dengan umur perkembangan anak. Dengan demikian dapat tercapai kondisi tumbuh kembang yang optimal. Untuk mencapai tujuan tersebut, maka sejak awal keadaan pertumbuhan dan perkembangan anak harus dipantau, sehingga bila ada gangguan atau penyimpangan dapat ditangani dengan benar. Untuk melakukan deteksi dini diperlukan suatu intrumen untuk mengetahui apakah anak telah bertumbuh dan berkembang secara normal (Nursalam \& Sri, 2013).

Intervensi dini adalah menelaah, mengamati perkembangan anak pada usia dini, antara 0-6 tahun. Dilihat apakah perkembangan anak ini masih masuk dalam kategori normal atau diluar dari yang normal. Secara psikologi, patokannya dapat dilihat dari bagaimana anak berinteraksi dengan orangtua, bagaimana anak merespon apa yang dilakukan orangtua terhadap anak. Juga dapat dilihat, apakah anak aman atau tidak, anak dapat beradaptasi dengan lingkungannya dan sejauh mana perkembangan pertumbuhan anak yang membutuhkan peralatan dalam stimulasi dan deteksi dini (Wong, Hartono, Andry, \& Sari, 2009). Anak yang dilakukan deteksi dini penyimpangan perkembangannya dapat diketahui lebih cepat dan dapat ditangani dengan hasil yang lebih baik (James P. Guevara, et al., 2013).

Alat deteksi dini merupakan suatu tes skrining yang telah distandardisasi. Berbagai macam pemeriksaan perkembangan dapat dikelompokan menjadi dua, yaitu tes untuk deteksi pertumbuhan dan tes untuk perkembangan itu sendiri. Untuk pertumbuhan, tes yang dapat digunakan adalah penentuan berat badan menurut tinggi badan dan pengukuran lingkar kepala. Sedangkan untuk perkembangan, tes yang dapat dilakukan adalah KPSP, KPAP, TDL, TKM, DDST, TDD, dan SDIDTK (Kemenkes, 2016).

Denver developmental screening (DDST) adalah sebuah metode pengkajian yang digunakan untuk menilai perkembangan anak umur 0-6 tahun. Dalam perkembangannya DDST mengalami beberapa kali revisi. Revisi terakhir adalah Denver II yang merupakan hasil revisi dan standardisasi dari DDST dan DDST- R (Revised Denver Developmental Screening Test). Perbedaan Denver II dengan skrining terdahulu terletak paa item-item tes, bentuk, interpretasi, dan rujukan (Dian, 2013). DDST memenuhi semua persyaratan yang diperlukan untuk metode skrining yang baik. Tes ini mudah dan cepat (15-20 menit), dapat diandalkan dan menunjukkan validitas yang tinggi. Penilaian DDST ini menilai perkembangan anak dalam empat sektor, yaitu penilaian terhadap personal sosial, motorik halus, bahasa, dan motorik kasar (Soetjiningsih, 2012). Alat ukur perkembangan lainya adalah SDIDTK, SDIDTK merupakan program pembinaan tumbuh kembang anak secara komprehensif dan berkualitas melalui kegiatan stimulasi, deteksi dan intervensi dini dalam penyimpangan tumbuh kembang pada masa 6 tahun pertama kehidupan (Kemenkes, 2016). 
Berdasarkan hasil survey, catatan medis dan wawancara peneliti kepada perawat puskesmas Basuki Rahmad dan orangtua yang memiliki anak usia toodler dibulan April 2018, didapatkan data ada 17 anak yang mengalami gizi kurang atau kurus dan 20 anak yang mengalami obesitas, dan juga ada 8 orang anak yang diduga megidap penyakit autis, untuk pemeriksaan tumbuh kembang anak rutin dilakukan setiap 3 bulan sekali oleh puskesmas ini, kegiatan tersebut dilakukan dengan bantuan dari para perawat, dokter, dan bidan, akan tetapi orangtua anak belum pernah secara mandiri melakukan deteksi dini tumbuh kembang anak, baik dengan metode DDST maupun SDIDTK.

\section{METODE PENELITIAN}

Jenis penelitian ini adalah penelitian kuantitatif dengan menggunakan rancangan Quasy eksperimen, pre post test equivalent without control group design dimana penelitian ini terdapat pengukuran awal (Pre test). Rancangan ini dipilih karena peneliti akan melakukan intervensi terhadap subyek penelitian. Pengukuran dilakukan sebanyak 2 kali kepada 2 kelompok, yaitu 1 kelompok dengan DDST dan kelompok yang lainnya dengan SDIDTK.

Proses pelaksanaan dari penelitian ini diawali dengan mengurus izin penelitian, setelah itu melakukan informed concent pada orang tua dan anak. Kemudian dilanjutkan dengan melakukan pengukuran perkembangan anak toodler (1-3) tahun sebelum intervensi DDST dan SDIDTK. Intervensi dalam penelitian ini diberikan selama 1 bulan yang dibagi menjadi 2 minggu untuk intervensi DDST dan 2 minggu untuk intervensi SDIDTK, setelah diberikan intervensi peneliti melakukan post test pada masing-masing kelompok intervensi DDST dan SDIDTK. Setelah itu, peneliti membandingkan hasil pre dan post test antara DDST dan SDIDTK.

\section{HASIL PENELITIAN}

Tabel. 1

Distribusi Frekuensi Perkembangan Anak Toddler dengan Metode DDST Sebelum dan Sesudah Diberikan Intervensi

\begin{tabular}{lcccc}
\hline \multirow{2}{*}{ Kategori } & \multicolumn{3}{c}{ DDST } \\
\cline { 2 - 5 } & Sebelum & $\begin{array}{c}\text { Persentase } \\
(\%)\end{array}$ & Sesudah & $\begin{array}{c}\text { Persentase } \\
(\%)\end{array}$ \\
\hline Abnormal & 3 & 30 & 0 & 0 \\
Meragukan & 3 & 30 & 3 & 30 \\
Normal & 4 & 40 & 7 & 70 \\
\hline Total & 10 & 100 & 10 & 100 \\
\hline
\end{tabular}

Berdasarkan tabel 1 dapat diketahui bahwa sebelum dilakukan intervensi ada 3 (30\%) orang anak yang tahap perkembangannya abnormal, 3 (30\%) orang anak yang tahap perkembangannya meragukan dan 4 (40\%) orang anak yang tahap perkembangannya normal. Setelah dilakukan intervensi selama 2 minggu sebagian besar yaitu 7 (70\%) orang anak yang tahap perkembangannya normal, dan 3 (30\%) orang anak yang tahap perkembangannya meragukan. 
Tabel. 2

Distribusi Frekuensi Perkembangan Anak Toddler dengan Metode SDIDTK Sebelum dan Sesudah Diberikan Intervensi

\begin{tabular}{lcccc}
\hline \multirow{2}{*}{ Kategori } & \multicolumn{4}{c}{ SDIDTK } \\
\cline { 2 - 5 } & Sebelum & $\begin{array}{c}\text { Persentase } \\
(\%)\end{array}$ & Sesudah & $\begin{array}{c}\text { Persentase } \\
(\%)\end{array}$ \\
\hline Abnormal & 2 & 20 & 0 & 0 \\
Meragukan & 4 & 40 & 3 & 30 \\
Normal & 4 & 40 & 7 & 70 \\
\hline Total & 10 & 100 & 10 & 100 \\
\hline
\end{tabular}

Berdasarkan tabel 2 dapat diketahui bahwa sebelum dilakukan intervensi ada 2 (20\%) orang anak yang tahap perkembangannya abnormal dan $4(40 \%)$ orang anak yang tahap perkembangannya meragukan. Setelah dilakukan intervensi selama 2 minggu sebagian besar yaitu 7 (70\%) orang anak yang tahap perkembangannya normal, dan $3(30 \%)$ orang anak yang tahap perkembangannya meragukan.

\section{Analisis Bivariat}

Tabel. 3

Skala Perkembangan Anak Toddler dengan Metode DDST dan SDIDTK Sebelum dan Sesudah Diberikan Intervensi.

\begin{tabular}{|c|c|c|c|c|c|c|}
\hline Variabel & \multicolumn{2}{|c|}{ Kelompok } & Mean & $\mathrm{SD}$ & $t$ value & $\mathrm{p}$ value \\
\hline \multirow{3}{*}{$\begin{array}{l}\text { Perkembangan Anak } \\
\text { Usia Toddler }\end{array}$} & $D D S T$ & $\begin{array}{l}\text { Sebelum } \\
\text { Setelah }\end{array}$ & $\begin{array}{l}7,50 \\
8,90\end{array}$ & $\begin{array}{l}2,07 \\
0,99\end{array}$ & $-3,096$ & 0,013 \\
\hline & \multirow{2}{*}{ SDIDTK } & Sebelum & 7,70 & 1,89 & \multirow{2}{*}{$-2,703$} & \multirow{2}{*}{0,024} \\
\hline & & Setelah & 8,80 & 0,92 & & \\
\hline
\end{tabular}

Berdasarkan tabel dapat dilihat bahwa rata-rata skor sebelum diberikan intervensi pada kelompok DDST adalah 7,50 dengan standar deviasi 2,07 dan kelompok SDIDTK adalah 7,70 dengan standar deviasi 0,99. Setelah dilakukan intervensi terdapat peningkatan skor tahap perkembangan pada kelompok DDST dan pada kelompok SDIDTK dengan masing-masing ( $\mathrm{t}$ value $=-3,096, \mathrm{p}$ value $=0,013)$ dan $(\mathrm{t}$ value $=$ $2,703$, $\mathrm{p}$ value $=0,024)$. Dapat disimpulkan bahwa ada pengaruh yang signifikan antara sebelum dan setelah diberikan intervensi DDST dan SDIDTK terhadap perkembangan anak usia toodler.

Tabel. 4

Perbedaan Perkembangan Anak Toddler Menggunakan Metode DDST dengan SDIDTK

\begin{tabular}{|c|c|c|c|}
\hline Kelompok & Mean & SD & $\mathrm{p}$ value \\
\hline$D D S T$ & 8.90 & 0,99 & 0,818 \\
\hline SDIDTK & $\underline{8,80}$ & $\underline{0,9}$ & \\
\hline
\end{tabular}

Berdasarkan tabel dapat dilihat bahwa tidak ada perbedaan yang signifikan antara kelompok DDST dengan kelompok SDIDTK dengan p-value $=0,818$. 


\section{PEMBAHASAN}

\section{Hasil Pengukuran Perkembangan Anak Toddler dengan Metode DDST Sebelum dan Sesudah Diberikan Intervensi}

Berdasarkan tabel 1 dapat diketahui bahwa sebelum dilakukan intervensi ada 3 (30\%) orang anak yang tahap perkembangannya abnormal dan $3(30 \%)$ orang anak yang tahap perkembangannya meragukan. Setelah dilakukan intervensi selama 2 minggu sebagian besar yaitu 7 (70\%) orang anak yang tahap perkembangannya normal, dan $3(30 \%)$ orang anak yang tahap perkembangannya meragukan.

Istilah tumbuh kembang tidak normal atau abnormal digunakan untuk menggambarkan anak yang perkembangan dan pertumbuhannya tidak konsisten dengan ekspetasi yang dianggap normal atau umum. Perkembangan yang abnormal di satu area kemungkinan bisa mempengaruhi perkembangan diarea lain, namun bisa juga tidak membawa pengaruh. Terdapat banyak penyebab perkembangan tidak normal, termasuk genetik, nutrisi yang tidak seimbang dan kesehatan ibu buruk saat kehamilan, terjadi cidera, dan tidak terstimulasi dengan optimal sehingga kurangnya kesempatan untuk belajar (Dewi \& Winarsih, 2017). Perkembangan dapat dioptimalkan dengan melakukan pemeriksaan perkembangan anak secara berkala untuk terus memantau tumbuh kembang anak. Beberapa faktor yang memengaruhi keberhasilan stimulasi antara lain kemampuan dasar individu, kesehatan, keluarga, lingkungan, serta keadaan sosial ekonomi (Lestari \& Hati, 2016; Sugeng, Tarigan, \& Sari, 2019). Selain itu, tumbuh kembang juga dipengaruhi oleh peran ayah dalam menstimulasi perkembangan anak usia sekolah, jika peran ayah yang memiliki stimulasi baik maka kemampuan tumbuh kembang anak akan memiliki peluang lebih optimal dibandingkan dengan anak yang tidak diberi stimulasi (Dewi \& Winarsih, 2017; Lestari \& Hati, 2016).

Salah satu cara untuk menghindari terjadinya resiko atau tumbuh kembang yang tidak normal adalah dengan cara mendeteksi tumbuh kembang anak sedini mungkin, Deteksi dini penyimpangan perkembangan pada anak merupakan tema global utama dalam pelayanan kesehatan anak secara modern. Kegiatan deteksi dimaksudkan untuk penapisan/penjaringan adanya penyimpangan tumbuh kembang anak, dan pengkajian faktor risiko yang mempengaruhi sehingga tindakan intervensi dapat dilakukan sedini mungkin (Chamidah, 2012). Selain itu, hal ini dilakukan juga untuk meminimalkan atau mencegah kecacatan yang mungkin timbul. Pemberian stimulasi atau rangsangan yang tepat juga dapat mencegah terjadinya ketidaknormalaan tumbuh kembang anak (Claudia et al., 2016). Stimulasi dari orangtua juga mempengaruhi tumbuh kembang anak, semakin baik peran orangtua maka akan semakin baik pula perkembangan motorik pada anaknya.

Perangkat skrining perkembangan terdiri dari beberapa perangkat salah satunya adalah Denver Development Screening Test (DDST). DDST adalah salah satu metode skrining terhadap kelainan perkembangan anak, tes ini bukanlah tes diagnostik atau tes IQ. DDST memenuhi semua persyaratan yang diperlukan untuk metode skrining yang baik (Desi, 2015). Tes ini mudah dan cepat (15-20 menit), dapat diandalkan dan menunjukkan validitas yang tinggi. Penilaian DDST ini menilai perkembangan anak dalam empat sektor, yaitu penilaian terhadap personal sosial, motorik halus, bahasa, dan motorik kasar (Soetjiningsih \& IGN, 2015).

Penilaian perkembangan anak dapat dilakukan oleh tenaga kesehatan utamanya peran perawat sebagai promotor kesehatan dan konselor dalam menggiatkan kegiatan skrining perkembangan, digunakan untuk membantu melakukan penjaringan (screening) dengan jalan deteksi dini perkembangan anak usia mulai dari usia 1 bulan 
sampai dengan 6 tahun dengan menggunakan tes DDST. Sehingga akan tercapai perkembangan anak yang optimal (Joni, 2015). Hasil penelitian Lystyanna, Nurjayanti, \& Yunitasari (2017) tentang Hubungan perilaku stimulasi terhadap perkembangan anak Pra sekolah (36-72 bulan) di kelompok bermain Tunas Bangsa Sidoharjo Kecamatan Jambon Kabupaten Ponorogo dengan menggunakan metode DDST dengan hasil, ada hubungan antara perilaku stimulasi yang diberikan oleh orang tua dengan perkembangan anak. Hasil yang sama dengan penelitian yang dilakukan oleh Joni (2015) tentang hubungan pola asuh orang tua terhadap perkembangan anak prasekolah (3-5 tahun) di PAUD Al-Hasanah. Sejalan dengan penelitian yang dilakukan oleh (Puspita, Makmuriana, \& Mariani, 2017) bahwa terdapat hubungan yang signifikan antara pola asuh orangtua dengan tumbuh kembang anak, dengan nilai $\mathrm{p}$ value $0,002<0,05$. Begitu juga hasil kesimpulan penelitian (Wayan, Asthiningsih, \& Muflihatin, 2018) tentang deteksi dini perkembangan balita dengan metode DDST di posyandu wilayah kerja puskesmas juanda samarinda yaitu setelah anak balita distimulasi selama 2 minggu, terdeteksinya secara keseluruhan aspek perkembangan pada balita dengan menggunakan metode DDST II didapatkan perkembangan anak normal berjumlah 93 balita (82,3\%), abnormal ada 2 balita (1,8\%), dan suspect ada 18 balita $(15,9 \%)$.

\section{Hasil Pengukuran Perkembangan Anak Toddler dengan Metode SDIDTK Sebelum dan Sesudah Diberikan Intervensi.}

Berdasarkan tabel 2 dapat diketahui bahwa sebelum dilakukan intervensi ada 2 $(20 \%)$ orang anak yang tahap perkembangannya abnormal dan $4(40 \%)$ orang anak yang tahap perkembangannya meragukan. Setelah dilakukan intervensi selama 2 minggu sebagian besar yaitu 7 (70\%) orang anak yang tahap perkembangannya normal, dan $3(30 \%)$ orang anak yang tahap perkembangannya meragukan.

Perkembangan yang matang ditandai dengan maturitas dari semua sistem organ, perolehan ketrampilan, kemampuan yang lebih siap untuk beradaptasi terhadap stres dan kemampuan orangtua dalam memberikan kegiatan-kegitan yang mampu menstimulasi perkembangan lewat bermain dan berkomunikasi, dan anak memperoleh kebebasan dalam mengekspresikan kreativitasnya (Wong et al., 2009).

Hal ini sesuai dengan pendapat (Yani \& Yuswo, 2012), bahwa salah satu faktor yang menghambat pertumbuhan dan perkembangan anak adalah stimulasi yang kurang terhadap anak. Stimulasi atau rangsangan khususnya dalam keluarga, misalnya peyediaan mainan, sosialisasi anak, serta keterlibatan ibu dan anggota keluarga lain terhadap kegiatan anak. Pendapat ini didukung juga oleh penelitian yang dilakukan oleh Zuanita \& Nurma (2016) tentang hubungan pola asuh orangtua dengan tingkat kemandirian pemenuhan ADS (aktivitas dasar sehari-hari) anak usia prasekolah didapatkan hasil dari 17 responden ada pengaruh terhadap aspek perkembangan anak pra sekolah dengan nilai ( $\mathrm{p}=$ value 0,000 ).

Dengan adanya kegiatan stimulasi, deteksi dini ini harapannya adalah ibu akan memiliki minat dalam upaya peningkatan dalam perawatannya anaknya terutama pada tumbuh kembangnya. Selain itu juga ibu akan memilki motivasi dan minat untuk melakukan intervensi dini pada pelayanan kesehatan, baik ke puskesmas maupun rumah sakit apabila mendapatkan temuan bagi balitanya terhadap penyimpangan tumbuh kembang, sehingga mampu memperkecil angka kejadian penyimpangan tumbuh kembang anak balita ataupun adanya tindak lanjut penatalaksanaan dari pelayanan kesehatan, sehingga anak balita yang mengalami masalah penyimpangan tumbuh 
kembang dapat ditangani dengan baik (Fitriani \& Oktobriariani, 2017). Penelitian yang dilakukan oleh (Putri, Lazdia, \& Oktriza, 2018) menjelaskan bahwa gangguan perkembangan pada anak bisa disebabkan oleh perawatan kesehatan, ini bisa terjadi karena perawatan kesehatan yang rutin dilakukan oleh keluarga dan tenaga kesehatan anak balita menjadi tidak memantau penyimpangan pertumbuhan dan perkembangan anak.

Faktor-faktor lain yang juga berpengaruh terhadap pertumbuhan dan perkembangan anak yaitu lingkungan, lingkungan tempat anak tingal sangat berperan penting dalam menetukan pertumbuhaan dan perkembangan anak baik fisik, perkembangan motorik, bahasa, emosi, maupun prilaku anak. Peran perawat dalam upaya deteksi perkembangan anak sudah dimulai sejak anak dalam kandungan, yaitu dengan melakukan pemeriksaan kehamilan secara berkala dan deteksi resiko tinggi saat kehamilan, kemudian menolong persalinan, serta merawat bayi dan ibu pasca persalinan (Nursalam \& Sri, 2013). Hasil penelitian lainnya juga menyebutkan bahwa metode SDIDTK sangat efekif dalam pengukuran perkembangan anak di posyandu Kucai kelurahan Teluk Kabupaten Banyumas (Rini \& Susilo, 2016). Penelitian yang dilakukan oleh (Nurfurqoni, 2017) juga menyebutkan metode SDIDTK efektif dalam pegukuran perkembangaan anak prasekolah.

Hasil penelitian lainnya juga menyebutkan bahwa metode SDIDTK sangat efekif dalam pengukuran perkembangan anak di posyandu Kucai kelurahan Teluk Kabupaten Banyumas (Rini \& Susilo, 2016). Penelitian yang dilakukan oleh Nurfurqoni (2017) juga menyebutkan metode SDIDTK efektif dalam pegukuran perkembangaan anak prasekolah.

Hasil penelitian Rizki, Budi, \& Destriatania (2016) dalam analisis kinerja petugas pelaksana stimulasi deteksi Intervensi dini tumbuh kembang (SDIDTK) balita dan anak prasekolah di wilayah kerja puskesmas Keramasan hasilnya adalah ada hubungan pengetahuan $(\mathrm{p}=0,000)$, motivasi $(\mathrm{p}=0,016)$, sarana prasarana $(\mathrm{p}=0,000)$, dana $(\mathrm{p}=0,001)$, dan sistem pengawasan $(\mathrm{p}=0,002)$ dengan kinerja petugas pelaksana SDIDTK. Tidak ada hubungan imbalan $(\mathrm{p}=0,599)$ dengan kinerja petugas pelaksana SDIDTK. Faktor yang paling berhubungan dengan kinerja petugas pelaksana SDIDTK adalah pengetahuan $(\operatorname{Exp}(B)=76,262)$. Kesimpulan dari penelitian tersebut adalah kinerja petugas pelaksana dalam pelaksanaan SDIDTK belum mencapai target yang ditetapkan Kemenkes (2016), dan hal ini dipengaruhi oleh faktor pengetahuan, motivasi, sarana prasarana, dana dan sistem pengawasan. Diharapkan kepada pihak puskesmas untuk melakukan berbagai upaya dalam meningkatkan kinerja petugas pelaksana dalam pelaksanaan skring dengan metode SDIDTK.

\section{Skala Perkembangan Anak Toddler di Wilayah Kerja Puskesmas Basuki Rahmad Kota Bengkulu dengan Metode DDST dan SDIDTK Sebelum dan Sesudah diberikan Intervensi.}

Berdasarkan tabel 3 dapat dilihat bahwa rata-rata skor sebelum diberikan intervensi pada kelompok DDST adalah 7,50 dengan standar deviasi 2,07 dan kelompok SDIDTK adalah 7,70 dengan standar deviasi 0,99. Setelah dilakukan intervensi terdapat peningkatan skor tahap perkembangan pada kelompok DDST dan pada kelompok SDIDTK dengan masing -masing ( $\mathrm{t}$ value $=-3,096, \mathrm{p}$ value $=0,013)$ dan $(\mathrm{t}$ value $=-$ $2,703$, $p$ value $=0,024)$.

Berdasarkan hasil penelitian terhadap 10 orang anak sebagai kelompok pengukuran perkembangan anak dengan metode DDST didapatkan bahwa nilai rata-rata 
skala perkembangan anak sebelum diberikan intervensi 7,50 dan setelah diberikan intervensi naik menjadi 8,90, dengan positif range sebesar 1,90 yang artinya ada 2 sample post tes intervensi nilainya lebih besar dari pada pre tes. Sedangkan hasil penelitian terhadap 10 orang anak sebagai kelompok pengukuran perkembangan anak dengan metode SDIDTK didapatkan bahwa nilai rata-rata skala perkembangan anak sebelum diberikan intervensi 7,70 dan setelah diberikan intervensi naik menjadi 8,80.

Hasil penelitian diatas menunjukan rata-rata pengukuran perkembangan anak mengunakan metode DDST, 2 kali lebih cepat menstimulasi peningkatan perkembangan anak usia toddler. Hal ini sesuai dengan pendapat (Nursalam \& Sri, 2013), DDST merupakan metode skrining terhadap perkembangan anak, tes DDST terbilang mudah dan cepat (15-20 menit), dapat diandalkan dan menunjukan validitas yang tinggi. Dari beberapa penelitian yang pernah dilakukan ternyata DDST secara efektif dapat mengidentifikasi antara 85-100 \% bayi dan anak prasekolah yang mengalami keterlambatan dalam perkembangan. Hal ini didukung juga dengan penelitian yang dilakukan oleh Nurlaila Wuri \& Riska (2017) di TK Pertiwi 1 Desa Porbowangi Kecamatan Buayan Kabupaten Kebumen, Hasil akhir menunjukan keefektifan penilaian tumbuh kembang anak dengan $(\mathrm{p}=$ value 0,001$)$. Penelitian lain juga menunjukan metode DDST lebih efektit terhadap penilaian perkembangaan anak prasekolah yang dilakukan oleh Lasiyati, Y \& Ervin (2016) di PAUD Al-Hidayah dengan nilai ( $\mathrm{p}=$ value $0,001)$.

Hasil penelitian rata-rata pengukuran perkembangan anak mengunakan metode SDIDTKpun mengalami peningkatan. Hal ini sesuai dengan pendapat Nursalam \& Sri, (2013) tentang stimulasi yang baik terhadap pertumbuhan dan perkembangan anak. Rangsangan (stimulasi) pada anak melalui panca indra akan merangsang pembentukan sinaps-sinaps sehingga dua atau lebih neuron akan saling berhubungan. Bila dua atau lebih neuron berhubungan melalui sinaps maka neuron-neuron tersebut aktif menghantarkan sinyal-sinyal elektrik pada saat bersamaan bila mendapatkan ransangan sensorik. Neuron-neuron yang sering menghantarkan sinyal elektrik akan semakin kuat hubungannya satu dengan yang lainya karena sering digunakan, disamping itu neuronneuron akan saling berkoordinasi satu dengan yang lainnya sesuai dengan fungsinya. Sebaliknya, bila tidak ada atau mendapatkan rangsangan maka sinap-sinaps akan mati atau terpangkas. Oleh karena itu neuron-neuron perlu dikejutkan dengan aliran listrik yang sama dan teratur agar sambungan antar neuron semakin kuat, kompleks dan menetap hingga anak menjadi dewasa. Oleh karena itu stimulasi atau rangsangan yang tepat akan membentuk kepribadian anak yang baik.

Sejalan dengan penelitian yang dilakukan oleh Lestari \& Hati (2016) tentang Pengaruh Pemberian Stimulasi pada Perkembangan Anak Usia 36-72 Bulan di Kecamatan Sedayu, dengan hasil ada pengaruh yang signifikan antara stimulasi yang diberikan orang tua dengan perkembangan anak dengan ( $p=$ value 0,001). Metode pengukuran perkembangan anak dengan metode SDIDTK sangat baik terhadap pengukuran perkembangan anak prasekolah hal ini sesuai dengan penelitian yang dilakukan oleh Rini \& Susilo (2016) di posyandu Kucai kelurahan Teluk Kabupaten Banyumas. Hasil akhir menunjukan keefektifan penilaian tumbuh kembang anak dengan ( $p$-value $=0,001)$ dengan skrining SDIDTK. 


\section{Perbedaan Rata-Rata Perkembangan Anak Toddler di Wilayah Kerja Puskesmas} Basuki Rahmad Kota Bengkulu dengan Pengukuran DDST dan SDIDTK

Berdasarkan tabel 4 dapat dilihat bahwa tidak ada perbedaan yang signifikan antara kedua metode dalam pengukuran perkembanagan anak toddler di wilayah kerja Puskesmas Basuki Rahmad Kota Bengkulu antara kelompok DDST dengan kelompok SDIDTK dengan $\mathrm{p}$-value $=0,818$ lebih besar dari pada nilai $\alpha=0,05$.

Dari pengalaman peneliti dilapangan meskipun tidak terdapat perbedaan yang signifikan antara kedua metode dalam pengukuran perkembanagan anak toddler di wilayah kerja Puskesmas Basuki Rahmad Kota Bengkulu, antara kelompok DDST dengan kelompok SDIDTK, akan tetapi ada hal yang menarik pada anak-anak tersebut, dimana anak dengan skrining perkembangan DDST lebih tertarik menjawab pertanyaan dan melakukan kegiatan dengan kuesioner DDST dikarenakan peneliti bersama anak ikut serta dalam penarikan garis umur untuk menetukan pertanyaan dan penyataan apa yang akan diberikan kepada anak tersebut, sedangkan untuk kuesioner SDIDTK sudah tersedia langsung pertanyaan dan pernyataannya sesuai umur anak.

Beberapa faktor lainnya menurut peneliti yakni pertanyaan untuk kuesioner DDST lebih banyak dari pada kuesioner SDIDTK yakni 12 pertanyaan sedangkan untuk SDIDTK hanya 10 pertanyaan, disamping itu metode DDST memang dikhususkan untuk menilai perkembangan anak sedangkan metode SDIDTK menilai pertumbuhan dan perkembangan anak.

Menurut Nursalam \& Sri (2013) DDST merupakan salah satu tes psikomotorik yang sering digunakan untuk menilai perkembangan anak. Dalam pelaksanaannya, DDST ini mudah dan cepat untuk digunakan serta mempunyai validitas yang relatif tinggi. setiap kemampuan/tugas dari masing-masing aspek perkembangan digambarkan dalam bentuk kotak persegi yang berurutan sesuai dengan usia anak. Dari beberapa penelitian yang pernah dilakukan ternyata DDST secara efektif dapat mengidentifikasikan antara $85-100 \%$ bayi dan anak-anak prasekolah yang mengalami keterlambatan perkembangan, DDST juga dapat menilai tingkat perkembangan anak yang sehat serta tidak menunjukan gejala kemungkinan adanya kelainan perkembangan dan juga dapat membandingkan performance anak-anak (Dian, 2013).

Sedangkan SDIDTK merupakan program pembinaan tumbuh kembang anak secara komprehensif dan berkualitas melalui kegiatan stimulasi, deteksi dan intervensi dini penyimpangan tumbuh kembang pada masa lima tahun pertama kehidupan. Adapun jenis kegiatan SDIDTK antara lain, deteksi dini penyimpangan pertumbuhan, skrining atau pemeriksaan perkembangan anak, penyimpangan mental emosional dan deteksi dini gangguan pemusatan perhatian dan hiperaktifitas (GPPH) pada anak (Nurlaila Wuri \& Riska, 2017).

\section{SIMPULAN}

Berdasarkan hasil penelitian didapatkan data sebelum dilakukan intervensi ada 3 orang anak yang tahap perkembangannya abnormal, 3 orang anak yang tahap perkembangannya meragukan dan 4 orang anak yang tahap perkembangannya normal. Setelah dilakukan intervensi menggunakan DDST selama 2 minggu sebagian besar yaitu 7 orang anak yang tahap perkembangannya normal, dan 3 orang anak yang tahap perkembangannya meragukan.

Sedangkan menggunakan metode SDIDTK didapatkan data sebelum dilakukan intervensi ada 2 orang anak yang tahap perkembangannya abnormal, 4 orang anak yang tahap perkembangannya meragukan dan 4 orang anak tahap perkembangannya normal. 
Setelah dilakukan intervensi selama 2 minggu sebagian besar yaitu 7 orang anak yang tahap perkembangannya normal, dan 3 orang anak yang tahap perkembangannya meragukan.

Terdapat pengaruh yang signifikan antara skor tahap perkembangan pada kelompok DDST dan pada kelompok SDIDTK sebelum dilakukan dengan setelah dilakukan intervensi.

\section{SARAN}

Adapun saran dalam penelitian ini adalah sebagai berikut:

1. Untuk peneliti selanjutnya diharapkan, melakukan penelitian untuk menilai keseteraan hasil pemeriksaan SDIDTK (KPSP) dan DDST (Denver II) pada anak toddler yang kondisi khusus dengan melihat karakteristik orangtua seperti dari status ekonomi, pendidikan keluarga, dan pengalaman merawat anak toddler.

2. Perlu dilakukan penelitian lebih lanjut yang mengukur kesetaran hasil pemeriksaan SDIDTK (KPSP) dan DDST (Denver II) pada tenaga kesehatan yang melakukan skrining di pelayanan primer.

3. Diharapkan tenaga kesehatan Puskemas Basuki Rahmad Kota Bengkulu, dapat melakukan pelatihan kepada ibu atau pengasuh anak dalam penilaian perkembangan anak toddler secara berkala, karena selain mudah tidak perlu waktu yang lama untuk melaksanakannya dan juga diharapkan para guru dapat mengikuti pelatihan dalam menilai tumbuh kembang anak agar selain mendidik guru juga dapat mengawasi pertumbuhan dan perkembangan muridnya sehingga menjadi daya tarik terhadap sekolah tersebut.

\section{DAFTAR PUSTAKA}

Cecily L., Betz. Showden., L. A. (2009). Buku Saku Keperawatan Pediatri (5th ed.). Jakarta: EGC

Chamidah, A. N. (2012). Deteksi Dini Gangguan Pertumbuhan dan Perkembangan Anak. Jurnal Pendidikan Khusus, 1(3)

Claudia, A., Almeida, D., Mendes, C., Rocha, I., Matos, V., Virginia, M., \& Peixoto, M. (2016). Use of a monitoring tool for growth and development in Brazilian children systematic review. Revista Paulista De Pediatria, 34(1), 122-131. https://doi.org/10.1016/j.rppede.2015.12.002

Desi. (2015). Pengaruh metode Gleen Doman dapat meningkatkan perkembangan anak Prasekolah usia 4-6 tahun dengan SDIDTK. Unsoed. Retrieved from http://keperawatan.unsoed.ac.id/sites/default/files/2015_skripsi_desi_pl-pl3.pdf

Dewi, A. K., \& Winarsih, B. D. (2017). Hubungan Peran Orangtua dalam Menstimulasi Perkembangan dengan Perkembangan Motorik Usia Prasekolah di TK Pertiwi Desa Kesambi Kab. Kudus. Publikasi Riset Kesehatan Untuk Daya Saing Bangsa, (1), 38-43

Dian, A. (2013). Buku Ajar Tumbuh Kembang dan Terapi Bermain Pada Anak (2nd ed.). Jakarta: Salemba Medika

Fitriani, I. S., \& Oktobriariani, R. R. (2017). Stimulasi , Deteksi dan Intervensi Dini Orang Tua terhadap Pencegahan Penyimpangan Pertumbuhan dan Perkembangan Anak Balita, 1(1), 1-9. Retrieved from ournal.umpo.ac.id/index.php/IJHS

James P. Guevara, Marsha Gerdes, Russell Localio, Yuanshung V. Huang, Jennifer Pinto-Martin, Cynthia S. Minkovitz, Diane Hsu, Lara Kyriakou, Sofia Baglivo, Jane Kavanagh, S. P. (2013). Effectiveness of Developmental Screening in an 
Urban Setting. Pediatric, 131(1), 30-37. https://doi.org/10.1542/peds.2012-0765 Joni. (2015). Hubungan Pola Asuh Orang Tua terhadap Perkembangan Bahasa Anak

Prasekolah (3-5 Tahun) Di PAUD Al-Hasanah Tahun 2014. Jurnal Paud Tambusai, 1(1), 42-48. https://doi.org/https://doi.org/10.31004/obsesi.v1i1.54

Kemenkes. (2016). Profil Kesehatan Indonesia Tahun 2015

Kuncoro, D. H. (2013). Hubungan antara Stimulasi Ibu dengan Perkembangan Motorik Halus dan Kasar pada Anak Usia Toddler di Paud Mekarsari Desa Pucangombo Tegalombo Pacitan. Universitas Muhammadiyah Surakarta

Lasiyati, Y \& Ervin, W. (2016). Hubungan Pola Asuh Orang Tua dengan Perkembangan Personal Sosial, Motorik Dan Bahasa Anak Prasekolah Di Paud Al- Hidayah. Jurnal Universitas Padjajaran, 9(2)

Lestari, P., \& Hati, F. S. (2016). Pengaruh Pemberian Stimulasi pada Perkembangan Anak Usia 12-36 The Influence of Stimulation in Children Aged 12-36 Months in Sedayu Regency , Bantul. Jurnal Ners Dan Kebidanan Indonesia, 4(1), 44-48. https://doi.org/http://dx.doi.org/10.21927/jnki

Lystyanna, R. D., Nurjayanti, D., \& Yunitasari, N. (2017). Hubungan Perilaku Stimulasi terhadap Perkembangan Anak Usia Prasekolah (36-72 Bulan) di Kelompok Bermain Tunas Bangsa Sidoharjo Kecamatan Jambon Kabupaten Ponorogo

Nurfurqoni, F. A. (2017). Pengaruh Modul Skrining Tumbuh Kembang terhadap Efektivitas Skrining Tumbuh Kembang Balita Studi Eksperimen Terhadap Kader di Puskesmas Merdeka dan Bogor Timur. Jurnal Bidan "Midwife Journal”, 3(2), 66-73. Retrieved from www.jurnal.ibijabar.org

Nurlaila Wuri \& Riska. (2017). Hubungan Tipe Pola Asuh Orang Tua dengan Perkembangan Psikososial Anak Usia Prasekolah di TK Pertiwi 1 Desa Purbowangi Kecamatan Buayan Kabupaten Kebumen. Jurnal Ilmiah Kesehatan Keperawatan, 33(1)

Nursalam, R. S., \& Sri. (2013). Asuhan Keperawatan Bayi dan Anak untuk Perawat dan Bidan. Jakarta: Salemba Medika

Puspita, D., Makmuriana, L., \& Mariani, A. R. (2017). Hubungan Pola Asuh Orangtua Terhadap Tumbuh Kembang Anak Dan Kejadian Obesitas Di Sekolah Dasar Swasta Bruder Melati Pontianak. Jurnal Keperawatan \& Kesehatan, 5(3). Retrieved from http://journal.stikmuhptk.ac.id/index.php/jkk/article/view/38

Putri, Y. R., Lazdia, W., \& Oktriza, L. (2018). Faktor yang Mempengaruhi Perkembangan Anak Balita Usia 1-2 Tahun di Kota Bukittinggi. REAL in Nursing Journal (RNJ), 1(2), 84-94. Retrieved from https://ojs.fdk.ac.id/index.php/Nursing/index

Rahardjo, S., Wayanti, S., \& Wardani, N. E. K. (2019). Pengaruh Fungsi Manajemen Pelaksana Kegiatan SDITK terhadap Cakupan SDITK Balita \& Anak Prasekolah. Jurnal Pamator, 12(1). https://doi.org/http://dx.doi.org/10.21107/pmt.v12i1.5173

Rini, A., \& Susilo. (2016). Implementasi Deteksi Gangguan Pertumbuhan Perkembangan Balita (Usia 1-5 Tahun) dengan Stimulasi, Deteksi dan Intervensi Dini Tumbuh Kembang (SDIDTK) di Posyandu Kucai Kelurahan Teluk Kabupaten Banyumas. Jurnal Keperawatan Scolatica. Stikes Jenderal Achmad Yani, 5(2)

Rivanica, R. (2019). Faktor-Faktor yang Berhubungan dengan Tumbug Kembang Anak Prasekolah. Jurnal 'Aisyiyah Medika, 3(2)

Rivanica, Rhipiduri, \& Oxyandi, M. (2016). Buku Ajar Deteksi Dini TumbuhKembang dan Pemeriksaan Bayi Baru Lahir. Jakarta: Salemba Medika 
Rizki, M., Budi, I. S., \& Destriatania, S. (2016). Analisis Kinerja Petugas Pelaksana Stimulasi Deteksi Intervensi Dini Tumbuh Kembang (Sdidtk) Balita dan Anak Prasekolah di Wilayah Kerja Puskesmas Keramasan, 7(3), 182-190. https://doi.org/ttps://doi.org/10.26553/jikm.2016.7.3.182-190

Soetjiningsih, R. (2012). Tumbuh Kembang Anak (2nd ed.). Jakarta: EGC Soetjiningsih, \& IGN, G. R. (2015). Tumbuh Kembang Anak. Jakarta: EGC

Sugeng, H. M., Tarigan, R., \& Sari, N. M. (2019). Gambaran Tumbuh Kembang Anak pada Periode Emas Usia 0-24 Bulan di Posyandu Wilayah Kecamatan Jatinangor of age 0-24 Months in Posyandu Jatinangor Subdistrict. JSK, 4(3), 96-101

Sulistyawati. (2014). Deteksi Tumbuh Kembang Anak. Jakarta: Salemba Medika

Wayan, N., Asthiningsih, W., \& Muflihatin, S. K. (2018). Deteksi Dini Perkembangan Balita dengan Metode Ddst II di Posyandu Wilayah Kerja Puskesmas Juanda Samarinda, 3(2), 367-374. https://doi.org/http://doi.org/10.22216/jen.v3i2.3149

WHO. (2017). Early Child Development. Retrieved from https://www.tandfonline.com/loi/gecd20?open=187\&year=2017\&repitition=0\#vo 1 187_2017

Wong, D. L., Hartono, Andry, \& Sari, K. (2009). Perawat dan Perawatan Pediatrik. (EGC, Ed.) (6th ed.). Jakarta. Retrieved from http://pustakaaceh.perpusnas.go.id/detail-opac?id=35683

Yani, \& Yuswo, L. (2012). Hubungan Pola Asuh Orang Tua Dengan Perkembangan Personal Sosial, Motorik Dan Bahasa Anak Prasekolah Di Paud Al-Hidayah. Jurnal Keperawtan Bina Sehat, 6(2). Retrieved from http://ejournal.stikesppni.ac.id/index.php/keperawatan-bina-sehat/article/view/19/0

Zuanita, \& Nurma, F. (2016). Hubungan Pola Asuh Orangtua dengan Tingkat Kemandirian Pemenuhan ADS (Aktivitas Dasar Sehari-hari) Anak Usia Prasekolah di TK BOPKRI Gondolayu Yogyakarta. Jurnal Keperawatan, 4(1) 